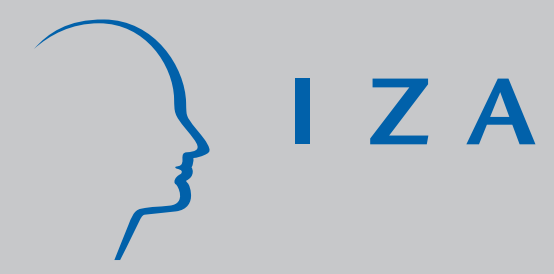

IZADP No. 1561

Career Choice, Marriage-Timing, and the Attraction of Unequals

Sylvain Dessy

Habiba Dj ebbari

April 2005 


\title{
Career Choice, Marriage-Timing, and the Attraction of Unequals
}

\author{
Sylvain Dessy \\ Université Laval, CIRPÉE \\ Habiba Djebbari \\ Université Laval, CIRPÉE \\ and IZA Bonn
}
Discussion Paper No. 1561
April 2005

\author{
IZA \\ P.O. Box 7240 \\ 53072 Bonn \\ Germany \\ Phone: +49-228-3894-0 \\ Fax: +49-228-3894-180 \\ Email: iza@iza.org
}

\begin{abstract}
Any opinions expressed here are those of the author(s) and not those of the institute. Research disseminated by IZA may include views on policy, but the institute itself takes no institutional policy positions.

The Institute for the Study of Labor (IZA) in Bonn is a local and virtual international research center and a place of communication between science, politics and business. IZA is an independent nonprofit company supported by Deutsche Post World Net. The center is associated with the University of Bonn and offers a stimulating research environment through its research networks, research support, and visitors and doctoral programs. IZA engages in (i) original and internationally competitive research in all fields of labor economics, (ii) development of policy concepts, and (iii) dissemination of research results and concepts to the interested public.
\end{abstract}

IZA Discussion Papers often represent preliminary work and are circulated to encourage discussion. Citation of such a paper should account for its provisional character. A revised version may be available directly from the author. 


\section{ABSTRACT \\ Career Choice, Marriage-Timing, and the Attraction of Unequals*}

Both men and women wish to have a family and a rewarding career. In this paper, we show that the under-representation of women in high-powered professions may reflect a coordination failure in young women's marriage-timing decisions. Since investing in a highpowered career imposes time strain, it precludes early participation in the marriage market. Delayed participation in the marriage market has a higher cost for women than for men because women have shorter fecundity horizons. Marriage prospects of high-powered women depend on the marriage-timing decisions of younger women. Under these assumptions, we show that women's marriage-timing decisions exhibit strategic complementarities. Coordination failures in women's marriage-timing decisions lead to persisting gender differences in career choices. Yet, differential fecundity is only necessary, but not sufficient to obtain gender inequality in high-powered professions. We discuss social changes that solve the coordination failure while achieving a Pareto-improvement in the society at large.

JEL Classification: J12, J16, J24

Keywords: marriage-timing, high-powered career, supermodular game, strategic complementarities, multiple equilibria, coordination failure

Corresponding author:

Habiba Djebbari

Université Laval

Department of Economics

Pavillon DeSève - Room 2290

Québec (QC) Canada G1K 7P4

Email: hdjebbari@ecn.ulaval.ca

\footnotetext{
* We thank Yann Bramoullé for insightful discussions, as well as seminar participants at Laval University. Sylvain Dessy acknowledges financial support from FQRSC.
} 


\section{Introduction}

The aim of this paper is to revisit the debate on the persistent under-representation of women in high-powered professions. ${ }^{1}$ Our motivation is twofold. First, there has been progress, worldwide, in the fight against all forms of discrimination against women (Browne [2002], UN [2004]). However, despite progress in civil rights, access to education and paid work, gender inequality in high-powered professions persists (ILO [2004]). Second, most of the gender gap in pay is due to the different career choices men and women make (Gunderson [1989], Blau and Kahn [2000]). This mere fact should provide women, as a group, with an incentive to attain gender equality in high-powered professions. It is therefore important to understand why current cohorts of women have not yet acted in this direction.

There is no consensus on the causes of the professional imbalances between the sexes. On one hand, there is a strand of the labor and demographics literature that views this imbalance as a reflection of human biology at work. It may be due to the "sexes' different biological dispositions" (Polachek [1981], Becker [1985], Browne [2002]), or to gender differences in fecundity horizons (Siow [1998]). This literature stresses the counter-productive consequences of public policy, viewed as an ill-advised interference with a natural process. On the other hand, another strand of the literature views under-representation of women in high-powered positions as a result of social barriers, either in the form of a 'glass ceiling' (Athey, Avery, and Zemsky [2000]; Albrecht, Bjorklund, and Vroman [2003]) or in the form of a 'social conditioning' (Gneezy, Niederle, and Rustichini [2003]).

We propose a marriage market-based explanation for the observed imbalance in highpowered career achievements between men and women. In our model, no forms of social

\footnotetext{
${ }^{1}$ In this paper, we focus on high-powered occupations, i.e. high profile jobs that require investment in high education. High-powered jobs are a subset of the International Labor Organization (ILO) high profile occupations. The ILO high profile class of jobs includes managerial and professional occupations. Managers include legislators, senior officials and corporate executives. Professional workers include physicists, chemists, mathematicians, architects, engineers and computer scientists. They also include doctors, lawyers and jurists, business professionals and economists, journalists, writers and artists, athletes, college and university teachers.
} 
barriers against women exist. Career choice and marriage-timing are joint decisions on the part of both men and women. An individual graduating from college may either delay participation in both the marriage and the labor market in order to invest in a higheducation necessary to have a high-powered career (Goldin [2004b]), or participate now in order to achieve a desired family life. ${ }^{2}$ Like their male counterparts, women aspire to have both a high-powered career and a family. But unlike their male counterparts, women who delay participation in the marriage market face a decline in their reproductive capability by the time they complete their career investment. Delaying therefore may impose a penalty in the form of reduced attractiveness in the marriage market. This is the only role human biology plays in our model.

Our research is closely related to Siow [1998] and Athey et al. [2000]. Siow [1998] develops a model of endogenous family-structure, which yields a unique equilibrium whereby women are professionally less-accomplished than their spouses. Biological differences in the relative length of the fecundity horizon are both necessary and sufficient for this result to obtain. In contrast, in our model, we show that biological differences are only sufficient, but not necessary, for gender imbalances in professional achievements to occur. In our model, unlike in Siow [1998], women's marriage-timing strategies exhibit strategic complementarities, which leads to a multiplicity of steady-state equilibria. Coordination failures in women's marriage-timing decisions result in the under-representation of women in highpowered positions. When such coordination failures occur, we expect married women to be professionally less accomplished than their spouses. In other words, the attraction of unequals should arise together with the under-representation of women in high-powered professions. Yet, because women prefer the equilibrium with equal professional achievements between spouses, any social device that can coordinate women's strategies towards this equilibrium ensures that gender equality in high-powered career achievements obtains and persists overtime, despite biological gender differences.

Athey et al. [2000] also develop a multiple-equilibrium model of women's relative rep-

\footnotetext{
${ }^{2}$ We assume that all women have access to an adequate technology for delaying participation marriage market, in the form of female-controlled contraceptives and/or safe abortion practices.
} 
resentation in top managerial positions within corporate firms. In their model, temporary affirmative action in favor of women can cause equal representation of men and women in top managerial positions to emerge and persists. Their model, however, do not treat career and family plans as joint decisions on the part of individuals. In our model, marriage and career are joint decisions for both men and women. As a result, in our model, unlike in Athey et al. [2000], the multiplicity of equilibria leads to a gender conflict: men prefer the equilibrium where they are professionally more accomplished than their spouses, whereas women prefer the equilibrium with gender equality in professional achievements. Consequently, a policy-induced social change that selects anyone of these equilibria does not necessarily represents a Pareto-improvement for the society at large. In particular, only policy-induced coordination mechanisms that resolve this conflict will obtain the strongest political support.

Our model rests on the following key assumptions. First, people marry to have children (Becker [1981]). Second, both career-making and the search for a marriage match take time and cannot be accomplished simultaneously (Goldin and Katz [2000]). Third, the opportunity cost of delaying marriage is higher for women than for men because of women's biological clock (Vella and Collins [1990], Siow [1998], Giolito [2003], Goldin [2004a]). Fourth, women base their marriage-timing and career decisions on the belief that their marriage prospects, if they choose to delay participation in the marriage market, depend on the marriage success of previous cohorts of high-powered women. Consequently, as more women delay marriage, the risk of remaining single decreases for career women, hence the expected payoff from delaying increases.

The rest of the paper is organized as follows. In the next section, we discuss the extent to which career and family choices are interrelated and motivate some of the crucial hypotheses underlying our model. In the second section, we present our marriage-market based model of gender difference in professional outcomes. In the third section, we discuss the policy implications of the model and offer concluding remarks. 


\section{Stylized Facts}

\section{A. Education and career choices.}

A recent publication by the International Labor Organization (ILO, 2004) provides extensive evidence of the under-representation of women in high-powered professions around the world. According to this study, this tendency is higher in developing countries than in developed regions. Yet, even in developed countries, the under-representation of women in high-powered jobs remains high. For instance, in 1999, women only represented $3.4 \%$ of the top corporate managers in Canada. In 2000, in the United States, merely $11.7 \%$ of the boards of the 500 top companies were women. In the United Kingdom, the women's share of top managerial positions decreased by $20 \%$ between 2002 and 2003. In France, only just 124 of 2325 top positions in the largest 200 firms are held by women. One may argue that this professional imbalance between the sexes is merely transitory- as it may take decades for an individual to reach a top position, while women's massive participation in the labor market is only a relatively recent phenomenon. However, since investment in high education is a pre-requisite for high-powered careers, persistent under-representation of women in some business, administration, science and technology majors (Browne [2002]) is an indication that women's career plans continue to differ from men's. Educational choices made by the current cohorts of young women provide us with a reasonably accurate picture of the future. Although equal numbers of men and women hold university degrees in most countries, males and females still make different academic choices. For instance, in 2003, only $21 \%$ of students enrolled in Canadian undergraduate computer science programs were female. At the same time, the female average enrolment in the 45 top European business schools was merely $27 \%$. As a result, gender inequality in high-powered professions is likely to be more than a transitory phenomenon.

\section{B. Career choices and gains from marriage.}

In the following, we present three stylized facts related to the gains from marriage. First, having children is the main purpose of marriage. Second, people may trade-off the quantity 
and quality of children. Third, on the marriage market, high-powered professionals are attracted to low profile professionals. Faced with a shortage of low profile professionals, high-powereds increasingly marry high-powereds.

First, the main motive for marriage is to have children (Becker [1981]). Although an increasing number of children are born out-of-wedlock and an increasing number of couples remain childless, trends on marriage and childbearing have not yet reversed. According to the U.S. Census 2002, $82 \%$ of married women have at least one child and $77 \%$ of never married women are childless.

Second, a trade-off in the quantity and quality of offspring may occur because of income and time constraints (Becker and Tomes [1976], Hanushek [1992]). Although we do not assume that women have a comparative advantage in home production (Becker [1985]), we maintain that gains from marriage are higher when one of the spouses is relatively more specialized in home production than the other spouse. Van Der Klaauw [1996] provides supporting empirical evidence. He finds that higher female wages are associated with lower gains from marriage.

Third, the gains from relative specialization have two implications for the matching on the marriage market. First, we expect the attraction of unequals, i.e. high-powered marrying low-powered, to produce the higher surplus from marriage. Second, as more women pursue careers, we expect the emergence of high-powered couples for which the surplus from marriage is lower. Empirical evidence is consistent with these effects. For instance, a worldwide survey of 1,192 executives in 2000 shows that $75 \%$ of married men live with a spouse who does not work. Male executive have in average 2.5 children. ${ }^{3}$ Among the female executives who are married, $74 \%$ live with a spouse who works full time. Female executive have in average 2.1 children. In addition, $68 \%$ of women consider that balancing career and personal life is the most challenging barrier to professional advancement. ${ }^{4}$

\footnotetext{
${ }^{3}$ Families and work institute, Catalyst and The center for work and family at Boston College, Carroll School of Management (2003).

${ }^{4}$ These figures are taken from another survey of 350 female executive in Canada produced by the Women Executive Network (2001).
} 


\section{Career or marriage?}

In the following, we argue that there is a trade-off between achieving a high-powered career goals and securing a marriage. We present three stylized facts: (1) when a high-powered career is desirable, men's and women's life sequence imply that they start by investing in their careers and then look for a marriage partner; (2) both men and women fear singlehood; (3) because of differential fecundity, women may want to marry earlier than men.

First, the achievement of a high-powered career involves time-intensive investments in education and early career development. Because of time strains, men and women who attempt to become high-powered professionals may not believe the search for a marriage partner to be compatible with their ambition. Oppenheimer [1988] suggests that starting a family may threaten career goals, as an early commitment to marriage may result in dropping out from university. For this same reason, Goldin and Katz [2000] shows that the availability of contraceptives allowed women to delay marriage and make career investments.

Second, delaying marriage may result in remaining single. There is evidence that, even in the United States, the fear of singlehood remains high among young people (Thornton and Freedman [1982]). The stigma attached to singlehood may vary under different legal, economic and social environments. What are the odds of remaining single for career women? The survey of 1,192 executives shows that $2 \%$ of men and $12 \%$ of women were never married. In a recent study, Brown and Lewis [2004] find that powerful women are at a disadvantage in the marriage market. Using a laboratory experiment in which men and women are asked to assess an opposite sex person described as a supervisor, a co-worker or an assistant, Brown and Lewis [2004] show that men are more likely to choose the subordinate compared to the high-powered woman for investing in a long-term relationship, while women are indifferent between the three categories of men. Another study shows that higher IQ are associated with higher chances to be ever-married for men but lower

chances for women (Taylor et al., 2004). The study suggests that higher IQ women are more likely to delay marriage in order to invest in a high-powered career, with some never 
marrying. This evidence suggests that career women face the risk of staying single because they have delayed marriage. Yet, it remains to understand why it is less the case for career men than for career women. This is our third point.

Men are fertile for a longer period than women. This is the sole gender difference between men and women. As a result, we expect women who delay marriage to incur a higher cost than men because men will find them less attractive as marriage partners than younger and more fertile women. Women may thus want to marry earlier than men (Vella and Collins [1990], Giolito [2003]). According to the United Nations Social Indicators for the period between 1991 and 1997, men do marry at an older age than women in all countries. In the developed regions, men and women are respectively 29 and 26 years old in average at the time of their marriage. Moreover, countries that exhibit the larger gaps in age at first marriage are also the countries that display the lower proportions of women holding high-powered careers.

\section{Role of the marriage history of career women.}

Our model assumes that the successes and failures of past cohorts of women in having both a high-powered career and family influence the career plans of subsequent cohorts. We draw support for our assumption from the economic history literature.

Goldin [1995] follows career and family choices of women in the past century in the United States. Past experience in the labor market and past fertility rates of working women helps explaining the choices of the subsequent cohorts of young women. As women born in the baby-boom era and graduating from college in the early seventies completes their fertility, they can act as guide to current college women.

In a more recent paper, Goldin [2004a] revisits this question. She finds that $88 \%$ of the baby-boom women married - a $4 \%$ drop compared to their mothers. Among married women, $19 \%$ remained childless by age 40 - a $9 \%$ rise. Yet, this was the first cohort of women to occupy high-powered professions in the United States. Goldin describes this cohort as having achieved "career then family". "Recognizing the problems with the biological clock" 
faced by the baby-boom cohort, the most recent cohort who graduated from college in the eighties aims at achieving both "career and family"(Goldin [2004a] p.9).

Goldin $[2004 b]$ focuses more specifically on the career and family achievement of "women at the top". Since the seventies, work plans of young women have remained steady, with close to $90 \%$ of them claiming they expect to work by age 35 . The number of young woman with professional degrees continues to rise. Yet, since 1980, females in a professional degree programs as a fraction of all college females have remained constant. Similarly, the largest increase in women's share of high-powered professions occurred during the eighties. These facts provide support for our assumption that women's past success at having a highpowered career and a family shows the way to subsequent cohorts of women. Mixed results obtained by the baby boom cohort may have convinced subsequent cohorts that if more young women were to opt for a career, they may too end up single or childless.

\section{Model}

This section presents a simple model that illustrates how women's representation in highpowered professions evolves overtime, across age-cohorts of ex ante identical women. We outline below the assumptions underlying the socioeconomic environment.

Time is discrete and extends over an infinite horizon. Initially, the population of single agents consists of three cohorts of respectively aged-3, aged-2 and aged-1 agents. All aged-3 agents are high-powered professionals (e.g., lawyers, physicians, or business executives) and have one-period left to live. Aged-2 agents are college-educated and all have two periods left to live (period 0 and period 1). Aged-1 agents each have three periods left to live. ${ }^{5}$ Their only activity in period 0 is to invest in a college education. There are $N$ men and $N$ women in each of the cohorts. ${ }^{6}$ The population of single agents evolves overtime as follows.

\footnotetext{
${ }^{5}$ Individuals in this age cohort are aged $17-18$ at the start of the period, which corresponds to the high-school-leaving age.

${ }^{6}$ We start with initial conditions where there is the same number of high-powered women and highpowered men. This is justified by the fact that both men and women always individually prefer to delay marriage and hold a high profile career, despite gender differential fecundity. Yet, we will show that even with favorable initial conditions, under-representation of women in high-powered occupation may follow
} 
In every period $t(t=0,1, \ldots)$, a new cohort of aged-1 agents -with an equal number, $N$, of men and women-enters the population of single agents.

All aged-2 agents face a marriage-timing decision. ${ }^{7}$ They must decide whether to participate in the marriage market and start a low-powered career in period 0, or to delay participation in both the marriage and the labor markets until the next period, in order to invest in a high education. An aged-2 agent who chooses this latter option will commit the entire period 0 to completing a graduate program (for example, in law, business or science) necessary to qualify for a high-powered job in period 1 when he or she becomes aged $3 .^{8}$ At that age, single agents each have one last chance to find a marital match. In the marriage market, they compete against younger women from the following aged-2 cohort.

Marriage (understood here as a union of individuals of opposite sex) is monogamous. In any period, an agent who finds a marital match stays married for the rest of his or her life. Likewise, an agent who finds no match after participating in the marriage market stays single his or her entire life, and thus derives a surplus $\delta>0$ from singlehood. For simplicity, we assume that this surplus is identical for both genders. To keep up with the economic literature on marriage and fertility (e.g., Becker [1981]; Edlund and Korn [2002]; Edlund [2004]; Greenwood, Guner and Knowles [2003]), assume that reproduction is the main motive for marriage. In other words, the surplus from a match in the marriage market is determined by the couple's reproductive success- the net gains from reproduction, including children, their quantity and quality. Success in reproduction requires two types of investments from the couple: time, including time necessary to nurture children's emotional and cognitive development, and financial resources including child care costs. Henceforth, the subscript and persists.

${ }^{7}$ According to the World Development Report 2000, in average, industrialized countries' women have completed 15 years of schooling, which corresponds roughly to an under-graduate university degree. Correspondingly, demographers, in the US for example, place the median age at first marriage for American women at around 22, which is the median age of a college graduate. Therefore, following the marriage and family literature (e.g., Allen and Kalish [1984]), we assume that the normative age for participating in the marriage market is above age-1.

${ }^{8}$ Available evidence indicates that the primary motive for delaying participation in the marriage market is to invest in a high-education (see for example Allen and Kalish [1984], and Houseknecht, Vaughan, and Statham [1987]). 
$f$ (respectively $m$ ) indexes women's (respectively men's) variables and parameters.

Assume there are two types of careers, low-powered and high-powered respectively. Assume also that an agent's professional empowerment is measured by the "rewards of money, power, leadership, prestige, and esteem" associated with the position held (Regan and Roland [1985]). Let $L$ and $H$ denote the degree of empowerment achieved by an agent in a low-powered job (denoted $L$ ) and a high-powered job (denoted $H$ ), respectively, where $H>L$. All marital matches in this environment feature dual-earner couples. ${ }^{9}$ Therefore a marital match between two professional agents is denoted as $\left(e_{f}, e_{m}\right)$. It specifies the degree of professional empowerment, $e_{g}$, for each marriage partner of gender $g(g=f, m)$. The set of possible combinations of dual-earner couples is given extensively by

$$
E=\{(L, L),(L, H),(H, L),(H, H)\}
$$

with typical element $e=\left(e_{f}, e_{m}\right)$. A match between two partners will be said to exhibit negative assortative mating if it is of the form $(L, H)$ or $(H, L)$. Both these types of matches correspond to the attraction of unequal professionals. In contrast, a marital match will be said to exhibit positive assortative mating if it is of the form $(L, L)$ or $(H, H)$.

Let $R: E \rightarrow \Theta$ be a function describing the relation between a marital match $e \in E$ and the marital surplus $\theta \in \Theta$ it generates to each of the partners. In other words, $R(e)$ denotes the reproductive success of a couple with match quality $e$.

Assumption 1. The function $R$ satisfies the following properties:

$$
\begin{aligned}
\text { (i) } R(L, H) & =\bar{\theta} \\
\text { (ii) } & R(H, L) \leq R(L, L)=R(H, H)=\underline{\theta},
\end{aligned}
$$

where $\underline{\theta}<\bar{\theta}$.

\footnotetext{
${ }^{9}$ This assumption can be relaxed without any additional gain in analytical insight. For example one of the spouses could be participating only in home production. He or she will be receiving a transfer $L$ form his or her partner as a reward for this occupation.
} 
Assumption 1 reflects the role played by gender differences in fecundity horizons (Siow [1998]; Giolito [2003]). Because women have a shorter fecundity horizon relative to men, by marrying at a younger age they maximize their reproductive success. However because reproductive success also depend on quality of offspring, a marital match of the form $(L, L)$ although susceptible to yield a high quantity of offspring, may be at a disadvantage when it comes to ensuring high quality to all its offspring. The reverse is true for a match of the form $(H, H)$. As a result, the surplus from both these matches is less than the one that would obtain from a match of the form $(L, H)$. That $R(H, L) \leq R(L, L)$ follows directly from differential fecundity, as women must delay marriage in order to invest in a high education necessary to become a high-powered professional.

Upon reaching age 2, all agents have preferences over the degree of empowerment, $e_{g}$, they derive from their occupation, and over the surplus derived from their chosen life style, i.e. single or married with a high-powered partner, or married with a low profile spouse. ${ }^{10}$ Let $\lambda$ denote an index operator that takes the value $\lambda=0$ if the agent ends up in singlehood, and $\lambda=1$ if married. Let $\widetilde{\theta}=\lambda \theta+(1-\lambda) \delta$ denote the surplus accrued to an agent of gender $g$, with marital status $\lambda$. As in François [1998] and Fernandez, Fogli, and Olivetti [2004], we assume that men and women have identical preferences. ${ }^{11}$

Let $\phi: E \times \Theta \rightarrow \Re$ denote the utility function representing these preferences, where $\phi\left(e_{g}, \widetilde{\theta}\right)$ denotes the level of life-time utility attained by an agent of gender $g \in\{f, m\}$, who has a career of type $e_{g}$, and gains a surplus $\widetilde{\theta}$ from his or her life style.

\footnotetext{
${ }^{10}$ As in Lundberg and Pollak [1993], households are composed of individual decision-makers. The interdependence between marriage partners in our model therefore operates solely through consumption of the surplus, which is the only household public good.

${ }^{11}$ In a recent survey of leaders of in the global economy, the Families and Work Institute [2004] finds no real support for the common wisdom that men are more ambitious than women when it comes to career preferences. Although this survey does find that in average more men than women aspire to be $\mathrm{CEO}$, it does also find that these observed gender differences rather than reflecting gender differences in preferences, are more likely to be consequences of social factors that give different shapes to women's and men's respective choice sets.
} 
Assumption 2. The function $\phi$ is strictly increasing in each of its arguments:

$$
\begin{aligned}
& \text { (i) for all } e_{g}^{\prime}>e_{g}, \quad \phi\left(e_{g}^{\prime}, \widetilde{\theta}\right)-\phi\left(e_{g}, \widetilde{\theta}\right)>0, \text { for each } \widetilde{\theta} \text { fixed } \\
& \text { (ii) for all } \widetilde{\theta}^{\prime}>\widetilde{\theta}, \quad \phi\left(e_{g}, \widetilde{\theta}^{\prime}\right)-\phi\left(e_{g}, \widetilde{\theta}\right)>0, \text { for each } e_{g} \text { fixed }
\end{aligned}
$$

Part $(i)$ of assumption 2 implies that given the surplus associated with his or her life style, any agent in this environment is always better off having a high-powered career than a low-powered one. Assumption 2 is consistent with findings from the literature on gender and family that both men and women (not just men) show a desire for high-powered professional careers (Regan and Roland [1985]; Goldin and Katz [2002]). Part (ii) implies that given his or her career choice, any agent in this environment is always better off having a higher surplus than a lower one.

Assumption 3. The function $\phi$ has strictly increasing differences in $\left(e_{g}, \widetilde{\theta}\right)$ on $E \times \Theta$ : for all $e_{g}^{\prime}>e_{g}$ and $\widetilde{\theta}^{\prime}>\widetilde{\theta}$,

$$
\phi\left(e_{g}^{\prime}, \widetilde{\theta}^{\prime}\right)-\phi\left(e_{g}, \widetilde{\theta}^{\prime}\right)>\phi\left(e_{g}^{\prime}, \widetilde{\theta}\right)-\phi\left(e_{g}, \widetilde{\theta}\right)
$$

Assumption 3 implies that for a typical agent in this environment, the incremental return to having a high-powered career is greater, when associated with a higher surplus derived from one's life style. Alternatively, one can easily check that this assumption also implies that the incremental return to having a high surplus is greater, when combined with a high-powered career:

$$
\phi\left(e_{g}^{\prime}, \widetilde{\theta}^{\prime}\right)-\phi\left(e_{g}^{\prime}, \widetilde{\theta}\right)>\phi\left(e_{g}, \widetilde{\theta}^{\prime}\right)-\phi\left(e_{g}, \widetilde{\theta}\right)
$$

To the extent that any surplus generated by a marital match is higher than the surplus derived from singlehood (i.e., $\delta<\underline{\theta}$ ), Assumption 3 also implies that all agents (male and female) are better off having both a high-powered career and a family life. In other words, higher career achievement complements higher family surplus in any agent utility function. 


\section{A. The Marriage Market}

In this environment, participation in the marriage market takes the form of single men and women sending and/or soliciting marriage offers. Agents who elect to participate in the marriage market compete by revealing the type of career (low-powered or high-powered) they have and the age-group (i.e., age-2 or age-3) they expect their marriage partner to fall into. There are no direct transfer payments involved between two marriage partners.

Assumption 4. The parameters $L, H, \bar{\theta}, \underline{\theta}$, and $\delta$ satisfy the following conditions:

$$
\phi(H, \underline{\theta})>\phi(L, \bar{\theta})>\phi(H, \delta)>\phi(L, \underline{\theta}) .
$$

Assumption 4 contains three main statements. The first statement (i.e., $\phi(H, \underline{\theta})>$ $\phi(L, \bar{\theta}))$ implies that in making their family and career plans, all individuals are willing to trade off a high-surplus marriage for a high-powered career, provided they can still marry. The second statement (i.e., $\phi(L, \bar{\theta})>\phi(H, \delta))$ implies that all agents would trade off a high-powered career for a high-surplus marriage in order to avoid singlehood. The third and last statement (i.e., $\phi(H, \delta)>\phi(L, \underline{\theta}))$ implies that all agents would trade off a lowsurplus marriage for singlehood to avoid being a low-powered professional. Assumption 4 is consistent with the evidence that although marriage has been losing its importance, it remains the most preferred lifestyle for both men and women.

Together, assumptions 1-4 imply that marriage-timing is not a trivial decision in this environment. In particular, because of differential fecundity, marriage participation rules differ for male and female, as men will never attain a level of utility $\phi(L, \bar{\theta})$ while women will never attain the level $\phi(H, \bar{\theta})$. For a single man aged 3 , the rule is as follows:

Step 1. First post a marriage offer in the age-2 segment of women's end of the marriage market. If the offer is picked up by an aged-2 single woman, marriage occurs and the successful aged-3 man has a lifetime utility, $\phi(H, \bar{\theta})$, while his low-powered, younger partner has lifetime utility level, $\phi(L, \bar{\theta})$. This type of marriage profile corresponds to what we refer to as the attraction of unequals. 
Step 2. If no aged-2 single woman picks up the offer, next posts an offer in the age-3 segment of the women's end of the market. If the offer is picked up by an aged-3 single woman, marriage occurs, and both partners attain an identical lifetime utility level, $\phi(H, \underline{\theta})$. This marriage between two high-profile individuals exhibits gender equality in professional achievements. An aged-3 man whose second offer is not picked up stays single for the rest of his or her life, in which case he will have a lifetime utility, $\phi(H, \delta)<\phi(H, \underline{\theta})$, by assumption 4 .

For aged-2 single men, the participation rule implied by assumptions 1-4 is summarized by the following proposition:

Proposition 1. Under assumptions 1-4, delaying participation in the marriage market until age 3 is always a dominant strategy for all aged-2 men.

Proposition 1 implies that no men ever elects to marry at age-2. Thus, any single aged-3 woman can only receive marriage offers from aged-3 single men. If she participates in the marriage market at age-2, a woman is guaranteed to find a spouse. This, however, means that she has to settle for a life-time utility level $\phi(L, \bar{\theta})$, which is less than the maximum, $\phi(H, \underline{\theta})$, she can attain under assumptions 1-4, were she to delay instead. But if she chooses to delay, there is a risk that she will have to settle for singlehood as a lifestyle. This strategy will yield a lower payoff $\phi(H, \delta)<\phi(L, \bar{\theta})$. In contrast to aged-2 men, single women from the initial age-2 cohort do not have a dominant marriage-timing strategy. In what follows, we discuss how women make their marriage-timing decisions.

\section{B. Interdependence of Marriage-Timing across Cohorts of Single Women}

In period $t$, any aged- 2 woman needs to consider whether to delay marriage $\left(s_{t}=1\right)$, or

not $\left(s_{t}=0\right)$. Delaying marriage allows women to invest in high-powered careers. But, this comes at a cost. When a woman delays, she knows she might not find a marital match because her reproductive success will be lower than the reproductive success of any aged-2 woman on the marriage market in the next period. Whether she finds a marital match or not ultimately depends on the marriage-timing of the following cohort of aged-2 single 
women. To evaluate the optimality of her decision to delay, a woman aged-2 must form expectations about the likelihood of her finding a spouse at age-3.

Let $\lambda_{t+1}$ be the marital status at period $t+1$ a woman aged-2 expects to get if at period $t$ she delays participation, where $\lambda_{t+1}=1$ means she marries, and $\lambda_{t+1}=0$ means she does not. Only women who were aged-3 in period $t-1(t=1, \ldots)$ have completed their participation in the marriage market in period $t$. Let $N_{t-1}^{3} \in[0, N]$ denote the number of single women who were aged 3 high-powered professionals in period $t-1$. A fraction $n_{t-1}^{3} / N_{t-1}^{3}$ of them ended up finding a marital match in period $t-1$. In period $t$, this fraction is an indicator of the rate of success in the marriage market of the age- 3 cohort.

Assumption 5. For any period $t>0$, any aged-2 woman believes that the conditional probability $P\left(\lambda_{t+1} / s_{t}=1\right)$ of finding a spouse at age-3 is given by

$$
P\left(\lambda_{t+1}=1 / s_{t}=1\right)=\left\{\begin{array}{cl}
n_{t-1}^{3} / N_{t-1}^{3} & \text { if } N_{t-1}^{3} \neq 0 \\
0 & \text { if } N_{t-1}^{3}=0
\end{array}\right.
$$

Assumption 5 states that young cohorts of single women always look to the past in order to learn about their prospects in terms of career and family. ${ }^{12}$ All aged-2 women believe that the conditional probability they will marry if they delay is equal to the rate of success in the marriage market of the previous cohort of aged-3 women who completed their participation on the marriage market in period $t$. Aged-2 women also anticipate that the following cohort of age- 2 women will base their marriage-timing decision on the marriage history of high-powered women.

We are interested in characterizing the equilibrium infinite sequence $\left\{N_{t}^{3}\right\}_{t=0}^{\infty}$ of single aged-3 high-powered professional. We assume that there are $N$ aged-3 single high powered women in period $0 .{ }^{13}$ Letting $N_{t}^{2}$ denote the number of aged- 2 women who delay

\footnotetext{
${ }^{12}$ As noted in the previous section, Goldin [1995] and Goldin [2004a] document, in the case of the US, the tendency of college-educated women to look to the family and career achievements of previous cohorts, in order to inform their own family and career choices.

${ }^{13}$ We start with initial conditions where there is the same number of high profile women and high profile men. This is justified by the fact that both men and women always individually prefer to delay
} 
participation in the marriage market, we have:

$$
\begin{aligned}
& N_{t}^{3}=N_{t-1}^{2} \text { for } t \geq 1 \\
& N_{0}^{3}=N \quad \text { for } t=0
\end{aligned}
$$

In order to characterize $\left\{N_{t}^{3}\right\}_{t=0}^{\infty}$, we need to determine $(i)$ the infinite sequence $\left\{N_{t-1}^{2}\right\}$ for $t \geq 1$, as well as $(i i) N_{0}^{2}$, the number of aged-2 women who delay marriage in period 0 . These objectives sketch the outline for the remaining of this section.

For any period $t \geq 1$, assumption 5 implies that the expected payoff from delaying marriage until period $t+1$ is given by:

$$
\frac{n_{t-1}^{3}}{N_{t-1}^{3}} \phi(H, \underline{\theta})+\left(1-\frac{n_{t-1}^{3}}{N_{t-1}^{3}}\right) \phi(H, \delta)
$$

while the payoff from not delaying is given by $\phi(L, \bar{\theta})$. Any woman aged-2 in period $t$ chooses to delay if and only if the following inequality holds:

$$
\frac{n_{t-1}^{3}}{N_{t-1}^{3}}>\frac{\phi(L, \bar{\theta})-\phi(H, \delta)}{\phi(H, \underline{\theta})-\phi(H, \delta)}
$$

When this inequality is satisfied, all aged-2 women rely on the favorable marriage history for aged-3 high-powered women. This favorable marriage history conveys the belief that delaying participation in the marriage market until age 3 is the normative behavior for aged-2 women. When (III.1) does not hold, all of them elect not to delay. We thus obtain the following participation rule for aged-2 single women in period $t \geq 1$ :

$$
N_{t}^{2}= \begin{cases}N & \text { if inequality (III.1) holds } \\ 0 & \text { otherwise. }\end{cases}
$$

In period 0 , there is no marriage history of high-powered women. How does an aged-2

marriage and hold a high profile career, despite gender differential fertility. Yet, we will show that that even with favorable initial conditions, under-representation of women in high profile occupation may follow and persists. 
woman make her marriage-timing decision? She anticipates that the following cohort of age-2 women will base their decision on how successful age-3 women are on the marriage market in period 0 . But, the success of age- 3 women in period 0 entirely depends on the decisions of age- 2 women. If $N_{0}^{2}$ aged-2 women decide to delay marriage, it means that $N-N_{0}^{2}$ are on the marriage market in period 0. According to assumptions 1-4 and proposition 1, men will marry them in priority. Remaining are $N_{0}^{2}$ single aged-3 men who propose to aged-3 women. Thus, $N_{0}^{2}$ aged-3 women end up married.

The consequences are two-fold. First, women from the initial age- 2 cohort know that history begins with their own family and career plans. Only when a critical number of aged-2 women in period 0 delay marriage will a favorable marriage history be created for high-powered women. This will happen when expected payoffs from $s_{t}=1$ are higher than $\phi(L, \bar{\theta})$, i.e. when:

$$
\frac{N_{0}^{2}}{N}>\frac{\phi(L, \bar{\theta})-\phi(H, \delta)}{\phi(H, \underline{\theta})-\phi(H, \delta)}=\gamma
$$

When a favorable marriage history is created, all future cohorts of aged-2 women will delay participation in the marriage market until they reach age-3: $N_{t}^{2}=N$ for all $t \geq 1$.

Second, the marriage-timing strategies of women in the initial age-2 cohort are complements. The higher the number of aged-2 women who delay is, the more likely women are to marry in the next period, and the higher the individual payoff from delaying marriage is. Since all agents are anonymous in this environment, each aged-2 woman in the initial cohort behaves strategically with respect to other aged-2 women. This strategic behavior creates a non-cooperative game situation between women in the initial age- 2 cohort, the outcome of which will determine the structure of the infinite sequence $\left\{N_{t}^{3}\right\}_{t=0}^{\infty}$, of highpowered women in this economy. In what follows, we describe the marriage-timing game aged-2 women from the initial cohort play in this environment.

\section{The Marriage-Timing Game.}

The game takes place in period 0 , and involves all women aged-2 in that period. We are interested in this game because its outcome creates a marriage history for high-powered 
women upon which future cohorts of aged-2 single women will based their marriage-timing decision.

Let $i$ index a single woman aged 2 in the first period, where $i \in I$ and $I=\{1, . ., N\}$. Hereafter, we refer to a single woman aged 2 in the first period as simply woman $i$. Denote as $S_{i}=\{0,1\}$ the finite strategy set of woman $i$, with typical element $s_{i} \in S_{i} . s_{i}=0$ means woman $i$ elects to participate in the marriage market when aged 2, while $s_{i}=1$ means she elects to delay participation in order to invest in a high education necessary to have a high-powered career in the second period.

We will also need the following definitions. Let $S=S_{1} \times \ldots, \times S_{N}$ denote the set of feasible joint strategies, with typical element $s=\left(s_{1}, \ldots, s_{N}\right)$. Observe that since $S_{i}$ is finite for all $i, S$ is also finite and contains a total of $2^{N}$ elements. Let $S_{-i}=S_{1} \times \ldots \times$ $S_{i-1} \times S_{i+1} \ldots \times S_{N}$ denote the set of feasible joint strategies for woman $i^{\prime}$ s competitors, with typical element $s_{-i} \in S_{-i}$. For all $i \in I$, define a function $P: S \rightarrow[0,1]$ by

$$
P(s)=\left\{\begin{array}{cl}
1 & \text { if } s_{i}=0, \forall s_{-i}, \\
\rho\left(N_{0}^{2}\right) \in[0,1] & \text { if } s_{i}=1 .
\end{array}\right.
$$

where $\rho\left(N_{0}^{2}\right)$ denotes the conditional probability that woman $i$ marries when aged 3 , if she elects to delay marriage until the next period, when a total number $N_{0}^{2}$ of women in her age-cohort chose that same strategy:

$$
N_{0}^{2}=\sum_{j=1}^{N} s_{j} .
$$

Since the higher $N_{0}^{2}$ is, the higher the likelihood that the next cohort of aged-2 women will choose to delay marriage, it follows that the function $\rho$ is increasing in its argument. More precisely:

$$
\begin{array}{ll}
\rho\left(N_{0}^{2}\right)=0 & \text { if } N_{0}^{2}<\gamma N, \\
\rho\left(N_{0}^{2}\right)=1 & \text { if } N_{0}^{2}>\gamma N .
\end{array}
$$


where $\gamma$ is as defined in (III.2).

Continuing our description of the normal-form of the women's marriage-timing game, we now turn our attention to the players' utility payoff functions. Denote woman $i$ 's payoff function as $u_{i}: S \rightarrow \Re$, defined by

$$
u_{i}(s)=s_{i} \psi(s)+\left(1-s_{i}\right) \phi(L, \bar{\theta})
$$

where

$$
\psi(s)=\rho\left(N_{0}^{2}\right) \phi(H, \underline{\theta})+\left[1-\rho\left(N_{0}^{2}\right)\right] \phi(H, \delta)
$$

is obtained by combining assumption 4 and (III.3). In other words, if woman $i$ plays the strategy $s_{i}=0$ in period 1 , when her competitors play the strategy profile $s_{-i}$, Equation (III.6) implies that she will receive a payoff

$$
u_{i}\left(0, s_{-i}\right)=\phi(L, \bar{\theta})
$$

while she will receive a payoff

$$
u_{i}\left(1, s_{-i}\right)=\psi(s)
$$

if she selects the strategy $s_{i}=1$, when her opponents select the profile $s_{-i}$.

A noncooperative game of marriage-timing for single women aged 2 in the first period is a triple $\Gamma=\left\langle I, S,\left\{u_{i}: i \in I\right\}\right\rangle$, consisting of a non-empty set of players $I$, a set $S$ of feasible joint marriage-timing strategies, and a collection of payoff function $\left\{u_{i}: i \in I\right\}$ where $u_{i}$ is a real-valued function defined on $S$ such that for any feasible joint strategy $s$ woman $i$ receives a payoff $u_{i}(s)$ given in (III.6) for all $i \in I$.

Observe that since the players have identical strategy sets (i.e., $S_{1}=S_{2}, \ldots=S_{N}$ ) and for all $i, j \in I, u_{i}(s)=u_{j}(s)$, therefore $\Gamma$ is a symmetric game. In what follows, we look for the Nash-equilibria of this game. 


\section{Symmetric Nash-Equilibria}

In this subsection, we show that the women's marriage-timing game $\Gamma$ only admits symmetric Nash equilibria. For this purpose we first show that $\Gamma$ is a supermodular game, also known as a game with strategic complementarities (Milgrom and Roberts [1990]).

Definition 1. (Milgrom and Roberts [1990]) $\Gamma$ is a supermodular game if for all $i$,

(i) $S_{i}$ is a compact subset of $\Re$;

(ii) $u_{i}$ is upper semi-continuous in $s_{i}$, for each $s_{-i}$;

(iii) $u_{i}$ is continuous in $s_{-i}$, for each $s_{i}$;

(iv) $u_{i}$ has a finite upper bound;

(v) $u_{i}$ has increasing differences in $\left(s_{i}, s_{-i}\right)$ on $S_{i} \times S_{-i}$.

Therefore to show that the marriage-timing game $\Gamma$ is supermodular, it suffices to show that it satisfies conditions $(i)-(v)$. We prove the following proposition in Appendix B.

Proposition 2. Under assumptions 1-5, the symmetric game of marriage timing, $\Gamma$, is supermodular.

Proposition 2 essentially states that the game $\Gamma$ exhibits strategic complementarities at the level of players' actions.

Corollary 1. (Topkis [1968]) Let

$$
B_{i}\left(s_{-i}\right)=\arg \max _{s_{i}} u_{i}\left(s_{i}, s_{-i}\right)
$$

be player $i$ 's best response to the strategy profile $s_{-i}$ played by the aggregate of her competitors. Then, for all $i$, and for all $s_{-i}^{\prime}>s_{-i}, B_{i}\left(s_{-i}^{\prime}\right)>B_{i}\left(s_{-i}\right)$.

Corollary 1 of proposition 2 states that the game $\Gamma$ has increasing best-responses. In other words, players' strategies are complements, implying that $\Gamma$ may have multiple purestrategy equilibria (Cooper and John [1988]). 
Our interest in supermodular games rests on four essential properties these games have. First, a supermodular game dispenses with the reliance on mixed-strategies to ensure existence of a Nash equilibrium, as such game always has an equilibrium in pure strategies, by virtue of Tarski's fixed-point theorem ${ }^{14}$. Indeed, Corollary 1 implies that conditions underlying Tarski's fixed-point theorem apply in this case, meaning that a Nash-equilibrium in pure strategies does exist. Second, even though the game may have mixed-strategy Nashequilibria, such equilibria are always unstable (Echenique and Edlin [2004]). Third, for a symmetric game, all pure-strategies Nash equilibria are symmetric because of strategic complementarities. Therefore, without loss of generality, we can restrict attention to symmetric Nash equilibria (SNE) in pure strategies. ${ }^{15}$ Fourth, when $\Gamma$ is a supermodular game with positive spillover, the SNE where all players choose their highest action, when it exists, is always Pareto-preferred (Cooper and John, [1988]; Levin [2003]). We prove the following Lemma in Appendix C.

Lemma 1. Under assumptions 1-5, the function $u_{i}$ is increasing in $s_{-i}$, for each $s_{i}$ fixed: $\forall\left(s_{-i}, s_{-i}^{\prime}\right)$ such that $s_{-i}^{\prime}>s_{-i}, u_{i}\left(s_{i}, s_{-i}^{\prime}\right)-u_{i}\left(s_{i}, s_{-i}\right) \geq 0$.

Lemma 1 states that the supermodular game $\Gamma$ has positive spillover. In other words, when woman $i$ 's competitors take their highest respective actions, her payoff is either unchanged or it increases.

We define a pure-strategy Nash equilibrium in terms of the payoffs players receive from various strategy profiles:

Definition 2. A pure-strategy profile $s^{*}$ is a strict SNE of $\Gamma$ if and only if $u_{i}\left(s^{*}\right)>$ $u_{i}\left(s_{i}, s_{-i}^{*}\right)$ for each $s_{i} \in S_{i}$ and each player $i \in I$.

Since $\Gamma$ is a symmetric game, in any pure-strategy Nash-equilibrium all women will choose to play the same strategy. Thus a pure-strategy profile $s^{*}$ is a SNE of $\Gamma$ if and only if $s_{i}^{*}=s_{j}^{*}$, for all $i \neq j, i, j \in I$, and $s^{*}$ is a Nash-equilibrium.

\footnotetext{
${ }^{14}$ Tarski's Fixed-Point Theorem: Suppose that $f:\{0,1\} \rightarrow\{0,1\}$ is a nondecreasing function, that is, $f\left(x^{\prime}\right) \geq f(x)$ whenever $x^{\prime} \geq x$. Then $f$ has a fixed point: $\exists x \in\{0,1\}$ such that $x=f(x)$.

${ }^{15} \mathrm{At}$ a SNE if all players select a strategy $s^{*}$, it is optimal for player $i$ to select $s_{i}=s^{*}$, as well.
} 
In what follows, we characterize the set of symmetric Nash equilibria when all women make their marriage-timing decision simultaneously. The following proposition proved in Appendix $D$ establishes our main result:

Proposition 3. Suppose

$$
\underline{\rho}<\frac{\phi(L, \bar{\theta})-\phi(H, \delta)}{\phi(H, \underline{\theta})-\phi(H, \delta)}<\bar{\rho} .
$$

where $\underline{\rho}=\rho(1)$ and $\bar{\rho}=\rho(N)$. Then, under assumptions 1-5, there exists two pure-strategy SNE: one where all members of the initial cohort of aged-2 single women delay, and another where none of them does.

The left-hand side of condition (III.10) states that the probability, $\underline{\rho}$, that a woman aged 2 in the period 0 who chooses to delay participation in the marriage market finds a spouse in the next period, when all same-age women choose not to delay, is sufficiently low. Notice that the right-hand side of (III.10) is what we previously defined as $\gamma$. We know from (III.5) that $\underline{\rho}$ can only take one of two values, 0 or 1 . Yet, for $N$ sufficiently large, $1 / N$ is always smaller that $\gamma$. Thus, $\underline{\rho}$ is likely to be equal to zero and the SNE where no women delay always exists.

When the right hand-side of condition (III.10) holds, a SNE where all women delay also exists. This is likely to occur because, by assumption $4, \gamma$ is always less than 1 , so that from (III.5). it follows that $\bar{\rho}=1$.

Thus, when condition (III.10) holds, there are two possible equilibrium sequences for the population of high-powered women: either $N_{t}^{3}=0$ all $t \geq 1, N_{0}^{3}=N$ given, or $N_{t}^{3}=N$ all $t \geq 0$. When the first sequence obtains as a long-term equilibrium, women's under-representation in the subset of high-powered professionals emerges from period 1 and persists throughout time. When the second obtains instead, equal representation will persist over time. Proposition 3 therefore implies that in societies where in general men continue to be professionally more accomplished than women despite equal education and labor market opportunities for both genders, coordination failure in women's marriagetiming decisions is a likely reason. 


\section{Summary and Discussion}

In this paper, we illustrate a mechanism which can cause a society to experience the emergence and persistence of imbalances in professional career achievements between men and women. In our model society, men and women only differ on the basis of the length of their fecundity horizons. Individuals' career and family plans reflect the interplay between their desire to have both a family and a rewarding career and gender differences in the length of the fecundity horizon. As a result of this interplay, agents have two strategies for their marriage timing. One is to delay marriage in order to invest in a high-powered career, and the other is to participate early in order to invest more in one's family life instead. While the interplay between individuals' life ambitions and human biology lead to all men having 'marriage delay' as a dominant strategy, it leads to strategic complementarities in women marriage-timing decisions. The non-cooperative game induced by these strategic complementarities highlights coordination failure in women's marriage-timing decisions as a cause of persisting gender differences in career choices.

We obtain this result without reference to either gender discrimination or any gender differences in preferences and/or abilities. Yet, unlike the existing literature emphasizing differential fecundity (Siow [1998]) persisting under-representation of women in highpowered positions is not a unique equilibrium. It is one of at least two, including one where gender equality in professional achievements persists. Because all women prefer the latter, they are likely to support social changes that coordinate their marriage-timing decisions towards gender equality. Any temporary action that can successfully coordinate the actions of the initial cohort of college-educated women towards delay of marriage, will have a long-term effect on the relative professional status of both genders.

However, our model reveals that while women strictly prefer the steady state equilibrium with equal representation of men and women in high-powered careers, men, in contrast, strictly prefer the steady state equilibrium where they are more professionally accomplished than their respective spouses. In the latter, they each attain a level of utility $\phi(H, \bar{\theta})$, whereas they each attain only $\phi(H, \underline{\theta})<\phi(H, \bar{\theta})$ in the former. In contrast 
women attain each a level of utility $\phi(L, \bar{\theta})$ under unequal professional achievements, whereas they each attain $\phi(H, \underline{\theta})>\phi(L, \bar{\theta})$ under gender equality. This situation creates a gender conflict in the distribution of high-powered careers among men and women that existing models abstract away from. This conflict may take form in men's opposition to all forms of social changes that could lead women to attain their Pareto-preferred steady state equilibrium, without compensating them for the forgone welfare from joining women in their Pareto-preferred steady state. For example, in opposition to such social changes, high-powered men may turn to foreign countries to find high-surplus brides, as has been recently documented in the case of some industrialized countries, including the United States. ${ }^{16}$

In contrast, all coordination mechanisms that cause assumption 1 to become violated have a better chance of achieving a Pareto-improvement in the society at large. For that purpose, such coordination devices must ensure that the following inequality obtains: $R(H, H) \geq R(L, H)=\bar{\theta}$. This inequality, unlike assumption 1 , states that the marital surplus achieved by a dual-earner family in which both partners are high-powered professionals is at least as high as one where the woman is less-accomplished than her high-powered partner. Relevant public policy actions may be those that mandate insurance coverage of fertility treatments for women over 35 (Buckles 2005). ${ }^{17}$ Alternatively, women may take time off after college in order to start a family, then return to graduate school, when their fertility is completed (Gilbert [2005]). Special scholarship program that target women returning to graduate school may therefore help achieve gender equality in career achievements, and thus help reduce the gender gap in pay.

\footnotetext{
${ }^{16}$ A 1999 report to the Congress by the United States Citizenship and Immigration Services (USCIS) reveals a rapid growth in the number of international matchmaking organizations assisting American men in their search for marriage-partners from foreign countries, including Asian countries and the former Soviet Union. The USCIS estimates that these organizations bring approximately 4,000 to 6,000 foreign brides a year into the United States.

${ }^{17}$ Buckles [2005] provides evidence that access to fertility therapies significantly increases women's wages at all ages.
} 


\section{Appendix}

\section{A. Proof of Proposition 1.}

Regardless of what other agents do, an aged-2 single man who elects to delay participation in the marriage market in order to invest in a high-education will face one of the probable three following events: $(i)$ he will marry a low-powered, younger woman; $(i i)$ he will marry a high-powered woman; or (iii) he will remain single. If the first of these events occurs, he will achieve his highest possible lifetime utility level, which is $\phi(H, \bar{\theta})$. He will achieve a lifetime utility level $\phi(H, \underline{\theta})<\phi(H, \bar{\theta})$ if the second event occurs, and a lifetime utility level $\phi(H, \delta)$ if the third occurs instead. However, if he elects not to delay, he will face one of two possible events. $(i)$ he will marry an aged-3, high-powered woman, or (ii) stay single for the rest of his life. The first event is associated with a payoff $\phi(L, \underline{\theta})$, while the second is associated with a payoff $\phi(L, \delta)$. The result then follows from assumption 4 .

\section{B. Proof of Proposition 2.}

To prove proposition 2 , first, observe that for all $i, S_{i}=\{0,1\}$, which is clearly a closed and bounded subset of $\Re$. Therefore property $(i)$ of a supermodular game is trivially satisfied. Second, to establish property $(i i)$ and (iii), it suffices to prove the following claim:

Claim 1. For all $i \in I, u_{i}: S \rightarrow \Re$ is continuous on $S$, where $S=S_{1} \times \ldots \times S_{N}$.

Proof. Since $S_{i}$ is finite for all $i$, therefore $S$ is also finite, as the Cartesian product of a finite number of finite sets. Indeed, $S$ has cardinal number $2^{N}$, which is finite since $N$ is a finite number. Therefore, by theorem ${ }^{18}, u_{i}$ is continuous on $S$. This establishes property (ii) and (iii) of a supermodular game

Third, to establish property (iv), it suffices to prove the following claim:

Claim 2. For all $i \in I, u_{i}: S \rightarrow \Re$ attains a maximum on $S$.

Proof. Since $S$ is a finite set, we also have that $u_{i}(S) \subset \Re$ is a finite set. And finite subsets of $\Re$ always contain their upper and lower bounds. It therefore follows that $u_{i}$ has

\footnotetext{
${ }^{18}$ Theorem (Topology). Any function defined on a finite set is continuous.
} 
a finite upper bound on $S$. This completes the proof of the claim

Fourth, the following claim establishes property (vi):

Claim 3. Let assumptions 1-5 hold. Then for all $i \in I, u_{i}: S \rightarrow \Re$ has strictly increasing differences in $\left(s_{i}, s_{-i}\right)$ on $S_{i} \times S_{-i}$ : for all $i \in I$, for all $s_{i}^{\prime}>s_{i}$ and $s_{-i}^{\prime}>s_{-i}$,

$$
u_{i}\left(s_{i}^{\prime}, s_{-i}^{\prime}\right)-u_{i}\left(s_{i}, s_{-i}^{\prime}\right) \geq u_{i}\left(s_{i}^{\prime}, s_{-i}\right)-u_{i}\left(s_{i}, s_{-i}\right)
$$

Proof. Suppose that for all $i \in I, s_{i}^{\prime}>s_{i}$ and $s_{-i}^{\prime}>s_{-i}$, but

$$
u_{i}\left(s_{i}^{\prime}, s_{-i}^{\prime}\right)-u_{i}\left(s_{i}, s_{-i}^{\prime}\right)<u_{i}\left(s_{i}^{\prime}, s_{-i}\right)-u_{i}\left(s_{i}, s_{-i}\right) .
$$

We will show that, since the function $\rho$ is monotone increasing by assumption, inequality (IV.2) leads to a contradiction.

Observe that inequality (IV.2) can also be written as follows:

$$
u_{i}\left(s_{i}^{\prime}, s_{-i}^{\prime}\right)-u_{i}\left(s_{i}^{\prime}, s_{-i}\right)<u_{i}\left(s_{i}, s_{-i}^{\prime}\right)-u_{i}\left(s_{i}, s_{-i}\right)
$$

all $i \in I$. Since $S_{i}=\{0,1\}$, for all $i$, take $s_{i}^{\prime}=1$ and $s_{i}=0$. Then, using (III.6), it can be shown that (IV.3) reduces to

$$
\psi\left(s^{\prime}\right)-\psi\left(s_{i}^{\prime}, s_{-i}\right)<0
$$

Define

$$
\begin{aligned}
& N_{2}^{\prime}=s_{i}^{\prime}+\sum_{j \neq 1}^{N} s_{j}^{\prime} \\
& \widetilde{N}_{2}=s_{i}^{\prime}+\sum_{j \neq 1}^{N} s_{j}
\end{aligned}
$$

Since $s_{j}^{\prime}>s_{j}$ for all $j \neq i$, therefore $N_{2}^{\prime}>\widetilde{N}_{2}$. From (III.7), inequality (IV.4) leads to

$$
\left[\rho\left(N_{2}^{\prime}\right)-\rho\left(\tilde{N}_{2}\right)\right][\phi(H, \underline{\theta})-\phi(H, \delta)]<0 .
$$


Clearly, this is a contradiction since $\phi(H, \underline{\theta})-\phi(H, \delta)>0$, by assumption 2 , and $\rho$ is an increasing function. Hence the result

The strict inequality in (IV.1) implies that for player $i$, the incremental gain from taking a higher action is higher, when her opponents also play their highest action. Condition (IV.1) can easily be shown to imply the following: for all $i$,

$$
u_{i}\left(s_{i}^{\prime}, s_{-i}^{\prime}\right)-u_{i}\left(s_{i}^{\prime}, s_{-i}\right) \geq u_{i}\left(s, s_{-i}^{\prime}\right)-u_{i}\left(s_{i}, s_{-i}\right) .
$$

In other words, when player $i^{\prime}$ s opponents take their highest action, the incremental gain to player $i$ is highest if she herself takes her highest action.

\section{Proof of Lemma 1.}

Let $\Delta_{i} \equiv u_{i}\left(s_{i}, s_{-i}^{\prime}\right)-u_{i}\left(s_{i}, s_{-i}\right)$. From (III.6), the difference $\Delta_{i}$ reduces to

$$
\Delta_{i}=\left[\psi\left(s_{i}, s_{-i}^{\prime}\right)-\psi\left(s_{i}, s_{i}\right)\right] s_{i}
$$

for all $s_{i} \in S_{i}$ and all $i \in I$. We want to show that $\Delta_{i} \geq 0$, for all $i \in I$.

Now, suppose instead that for some $i$, and for all $s_{-i}^{\prime}>s_{-i}, \Delta_{i}<0$. Then from (III.7)), it can be shown that inequality $\Delta_{i}<0$, reduces to

$$
\left[\rho\left(\widehat{N}_{2}\right)-\rho\left(N_{2}\right)\right][\phi(H, \underline{\theta})-\phi(H, \delta)] s_{i}<0
$$

where

$$
\begin{aligned}
& \widehat{N}_{2}=s_{i}+\sum_{j \neq i} s_{j}^{\prime} \\
& N_{2}=s_{i}+\sum_{j \neq i} s_{j} .
\end{aligned}
$$

Since $s_{-i}^{\prime}>s_{-i}$, it follows that $\widehat{N}_{2}>N_{2}$ by construction, implying that $\rho\left(\widehat{N}_{2}\right)-\rho\left(N_{2}\right) \geq$ 0. Clearly, we reach a contradiction, since, by assumption 2 , the function $\phi$ is strictly 
increasing in both its arguments, and $s_{i} \in\{0,1\}$. This completes the proof.

\section{Proof of Proposition 3.}

The proof is divided in two claims:

Claim 1. The strategy profile $s^{0}$ such $\forall i, s_{i}^{0}=0$, is a SNE of $\Gamma$.

Proof. Using (III.8) and (III.9), it follows from definition 2 that the profile $s^{0}$, is a strict pure-strategy SNE of $\Gamma$ if and only the following condition is always satisfied for all $i$ :

$$
\phi(L, \bar{\theta})>\phi(H, \underline{\theta}) \underline{\rho}+(1-\underline{\rho}) \phi(H, \delta)
$$

The result then clearly follows from (III.10)

Claim 2. The strategy profile $s^{1}$ such $\forall i, s_{i}^{1}=1$, is a SNE of $\Gamma$.

Proof. The proof follows in the same manner as in Claim 1. Hence the result.

\section{References}

[1] Allen, Suzanne M., and Richard A. Kalish (1984). "Professional Women and Marriage". Journal of Marriage and the Family, 46(2): 375-382.

[2] Albrecht, James, Anders Bjorklund, and Susan Vroman (2003). "Is there a glass ceiling in Sweden?" Journal of Labor Economics, 21 (1): 145-177.

[3] Arulampalam, Wifi, Allison Booth and Mark Bryan. (2004). "Is There a Glass Ceiling over Europe? Exploring the Gender Pay Gap." IZA Discussion Paper 1373.

[4] across the Wages Distribution

[5] Becker, Gary (1981). A Treatise on the Family. Harvard University Press.

[6] Becker, Gary (1985). "Human capital, effort and the sexual division of labor." Journal of Labor Economics. 3 (1): S33-S58. 
[7] Becker, Gary and Nigel Tomes (1976). "Child Endowments and the Quantity and Quality of Children" Journal of Political Economy, 84 (4): S143-S162.

[8] Bergstrom, Theodore and Mark Bagnoli (1993). "Courtship as a Waiting Game." Journal of Political Economy 101(1): 185-202.

[9] Blau, Francine and Lawrence Kahn (2000). "Gender differences in pay." NBER Working Paper No. 7732.

[10] Brown, Stephanie and Brian Lewis (2004). "Relational dominance and mate-selection criteria: evidence that male attend to female dominance." Journal of Evolution and Human Behavior, 25: 406-415.

[11] Browne, Kingsley R. (2002). Biology at Work: Rethinking Sexual Equality. Rutgers University Press, New Jersey.

[12] Buckles, Kasey. (2005). "Stopping the Biological Clock: Fertility Therapies and the Career-Family Trade-off". Unpublished manuscript, Boston University.

[13] Cherlin, Andrew (1980). "Postponing marriage: the influence of young women's work expectations." Journal of Marriage and the Family. 42 (2): 355-365.

[14] Chattopadhyay, Raghabendra and Esther Duflo (2004) "Women as Policy Makers: Evidence from a Randomized Policy Experiment in India". Econometrica 72(5): 14091443.

[15] Cooper, Russell and Andrew John (1988), "Coordination Failures in A Keynesian Models", Quarterly Journal of Economics, 103(3): 441-463.

[16] Echenique, F. and A. Edlin (2004) "Mixed Strategy Equilibria are Unstable in Games of Strategic Complements". Journal of Economic Theory, 118: 61-79.

[17] Edlund, Lena (2004). "Sex and the City". Scandinavian Journal of Economics. Forthcoming. 
[18] Edlund, Lena and Rohini Pande (2002) "Why have Women Become Left-Wing: the Political Gender Gap and the Decline in Marriage". Quarterly Journal of Economics, 117:. 917-961.

[19] Edlund, Lena and Evelyn Korn (2002). "A Theory of Prostitution". Journal of Political Economy, 110: 181-214.

[20] Escriche, Luisa, Gonzalo Olcina and Rosario Sanchez (2004). "Gender discrimination and intergenerational transmission of preferences." Oxford Economic Papers, 56: 485511.

[21] Fernandez, Raquel, Alessandra Fogli, and Claudia Olivetti (2004). "Mothers and Son: Preferences Formation and Female Labor Force Dynamics". Quarterly Journal of Economics, $119(4):$ 1249-1299.

[22] François, Patrick (1998). "Gender discrimination without gender difference: theory and policy responses." Journal of Public Economics. 68: 1-32.

[23] Gilbert, Neil (2005). "What do women really want?" Public Interest. 158.

[24] Giolito, Eugenio P. (2003). "A Search Model of Marriage with Differential Fecundity". Manuscript, Department of Economics, University of Maryland.

[25] Gneezy, Uri, Muriel Niederle, and Aldo Rustichini (2003). "Performance in Competitive Environments: Gender Differences". The Quarterly Journal of Economics, 118(3): 1049-1074.

[26] Goldin, Claudia (2004a) "The Long Road to the Fast Track: Career and Family", NBER Working Paper No. 10331.

[27] Goldin, Claudia (2004b). "From the Valley to the Summit: A Quiet Revolution that Transformed Women Work", NBER Working Paper, N. 10335.

[28] Goldin, Claudia (2002) "A Pollution Theory of Discrimination: Male and Female Occupations and Earnings". NBER Working Paper No. 8985. 
[29] Goldin, Claudia and Lawrence F. Katz (2000) "Career and Marriage and the Age of the Pill." American economic Review, Vol 90(2). Papers and Proceedings, pp: 461-465.

[30] Goldin, Claudia (1997) "Career and Family: College Women Look to the Past", , Gender and Family Issues in the Workplace, New York. In R. Ehrenberg and F. Blau, eds., Russell Sage Foundation Press: 20-58.

[31] Greenwood, Jeremy, N. Guner, and J. Knowles (2003), "More on Marriage, Fertility, and Distribution of Income". International Economic Review, Vol. 44(3): 827-862.

[32] Gunderson, Morley (1989). "Male-female wage differentials and policy responses." Journal of Economic Literature, 27(1): 46-72.

[33] Hadfield, Gillian (1999). "A coordination model of the sexual division of labor." Journal of Economic Behavior and Organization, 40: 125-153.

[34] Hanushek, Eric (1992). "The trade-off between child quantity and quality". Journal of Political Economy 100 (1): 84-117.

[35] Houseknecht Sharon K., Suzanne Vaughan, and Anne Statham (1987). "The Impact of Singlehood on the Career Patterns of Professional Women". Journal of Marriage and the Family, 49(2): 353-366.

[36] ILO (2003). Yearbook of Labour Statistics. Geneva.

[37] ILO (2004) Breaking through the glass ceiling: women in management. Geneva.

[38] Lundberg, Shelly and Robert A. Pollak (1993). "Separate Spheres Bargaining and Marriage Market", Journal of Political Economy, 101(6): 988-1010.

[39] Levin, Jonathan (2003), "Supermodular Games", Lectures Notes, Department of Economics, Stanford University.

[40] Milgrom, P. and J. Roberts (1990). "Rationalizability and Learning in Games with Strategic Complementarities". Econometrica, 58: 1255-1278. 
[41] Oppenheimer, Valerie (1988). "A theory of marriage timing". American Journal of Sociology.94 (3): 563-591.

[42] Polachek, Solomon (1981). "Occupational self-selection: a human capital approach to sex differences in occupational structure." Review of Economics and Statistics. 63 (1): 60-69.

[43] Qian, Zhenchao and Samuel Preston (1993). "Changes in American marriage, 1972 to 1997: Availibility and forces of attraction by age and education." American Sociological Review. 58 (4): 482-495.

[44] Regan, Mary C. and Helen E. Roland (1985). "Rearranging Family and Career Priorities: Professional Women and Men of the Eighties". Journal of Marriage and the Family, 47(4): 985-992.

[45] Siow, Aloysious (1998). "Differential Fecundity, Markets, and Gender Roles". Journal of Political Economy, 106 (2): 334-354.

[46] Taylor, Michelle, Carole Hart, George Smith, Lawrence Whalley, David Hole, Valerie Wilson and Ian Deary (2004). "Childhood IQ and marriage by midlife: the Scottish Mental Survey 1932 and the Midspan studies." Journal of Personality and Individual Differences. Forthcoming.

[47] Thornton, Arland and Deborah Freedman (1982). "Changing attitudes towards marriage and single life." Family Planning Perspectives. 14 (6): 297-303.

[48] Topkis, D. (1968) Ordered Optimal Decisions. Ph.D. Dissertation, Stanford University.

[49] Vella, Franck and Sean Collins (1990). "The value of youth: equalizing age differentials in marriage". Applied Economics.22: 359-373.

[50] Van Der Klauuw, Wilbert (1996). "Female labour supply and marital decisions: a life-cycle model." Review of Economic Studies. 63 (2): 199-235. 